\title{
An Interval Programming-based Traffic Planning Model for Urban Vehicle Emissions Management
}

\author{
Shen Wang ${ }^{1}$, Yulei Xie ${ }^{1}$, Ye Tang ${ }^{1}$, Hongkuan Zang ${ }^{2}$, Zhe Wang ${ }^{1}$ \\ ${ }^{1}$ Key Laboratory of Regional Energy System Optimization, Ministry of Education, \\ North China Electric Power University, Beijing China \\ ${ }^{2}$ Chinese Academy For Environmental Planning, Anwai dayang lane, Beijing China \\ Email: xieyulei850228@yahoo.com.cn, wangshen777@yahoo.cn
}

Received December, 2012

\begin{abstract}
An interval linear traffic planning model is developed for supporting vehicle emissions limited under uncertainty. The interval linear traffic planning model can address uncertainties of traffic system and vehicle emissions related to system costs and limitation of emission. The interval linear traffic planning model is applicable to complex traffic system. One virtual city as our study object was taken by using the interval linear traffic planning model. In this study, one virtual case and a scenario are provided for three planning periods. The results indicate that the interval linear traffic planning model can effectively reduce the vehicles emission and provide strategies for authorities to deal with problems of transportation system.
\end{abstract}

Keywords: Traffic System; Vehicle Emissions; Traffic Flow; Interval Linear Programming; Interval Number

\section{Introduction}

As the natural and economic resources are limited, reasonable development of the transportation system between cities is significant in developing and industrialized countries. Vehicle emissions has brought about seriously air pollution in the world, for example, Dense fog always happened in winter of Beijing because of vehicle emissions. Vehicle emissions management is a major challenge for policy makers on the transportation system.

Previously, a number of transportation planning models were developed for supporting traffic environment management $[3-9,13,14]$ However, most of the previous studies only focused on the transportation planning in a community or a region, and rarely developed optimization models for inter-community transportation planning. Although published literatures are increasing, they focus mostly on the prediction of changes in air quality caused by short-term planning [1,5-7,13,14]. In fact, researches on reducing controlling and controlling vehicle emissions by transportation planning are still deficiency due to the uncertainties of the traffic systems[2,7,11,13,14]. Therefore, in this study the objective is to develop an interval optimization model for inter-community transportation planning and vehicle emissions management. The model will be applied to a virtual case, and generate compromise optimized scheme under diversified system conditions $[7,10]$.

\section{Modeling Development}

In most transportation planning, decision makers are generally responsible for improving traffic safety and traffic flux, but they seldom consider the questions of system cost and traffic environmental protection. Therefore, this study will focus on how to allocate funds reasonably, and realize the environmental goals which is desired in transportation planning in the future[3,4,12]. In addition, there are a large number of uncertainties such as traffic flow, public perception, driver behavior and so on. To deal with uncertainties, a number of methods were developed, including interval programming, fuzzy mathematical programming, and stochastic programming. Interval linear programming (ILP) is an alternative for handing with uncertainties [13,14]. ILP does not require distribution information for its parameters since interval are acceptable for the uncertain inputs $[4-6,9,12,13]$.The ILP model can be expressed as follows $[4-6,11,14]$.

$$
\operatorname{Min} f^{ \pm}=C^{ \pm} X^{ \pm}
$$

subject to:

$$
\begin{gathered}
A^{ \pm} X^{ \pm} \leq B^{ \pm} \\
X^{ \pm} \geq 0
\end{gathered}
$$

where $\quad A^{ \pm} \in\left\{R^{ \pm}\right\}^{m \times n}, \quad B^{ \pm} \in\left\{R^{ \pm}\right\}^{m \times 1}, \quad C^{ \pm} \in\left\{R^{ \pm}\right\}^{1 \times m}$, $X^{ \pm} \in\left\{R^{ \pm}\right\}^{n \times 1}$ and $R^{ \pm}$denotes a set of interval variables. 
Decision makers can project transportation planning problem in terms of minimizing the system cost with reasonable traffic structure and seduction of vehicle emission. China's State Environmental Protection Administration upgraded emission controls to National Standard III, equivalent to European III standards [1,5,8].

Then, in this study, vehicles are classified into three types by exhaust levels: low emission vehicles; middle emission vehicles and high emission vehicles. High emission vehicles include light commercial vehicles (>1,305 kg, gasoline); middle emission vehicles include passenger cars, light commercial vehicles $(<1,305 \mathrm{~kg}$, gasoline); and low emission vehicles include passenger car and so on. Parameters and system objectives are described as intervals to deal with the uncertainties in the transportation planning system[13]. The constraints are to describe relationships among decision variables and environmental limits. Three periods are considered in each year. Based on interval linear programming, the objective function is formulated as a sum of the follows:

The objective of this model is to minimize system cost, which include (1) fuel cost, (2) traffic management expense, (3) costs for capacity expansion of traffic facilities, (4) maintenance expense and (5) vehicle emission fee:

$$
\min f^{ \pm}=\left\{\begin{array}{c}
(1)+(2)+(3)+(4)+(5) \\
\quad \text { if building new thoroughfare } \\
(1)+(2)+(4)+(5) \\
\quad \text { if keeping current facilities }
\end{array}\right.
$$

Fuel cost:

$$
\text { (1) }=\sum_{f c}^{3} \sum_{t=1}^{3} \sum_{r=1}^{r s} \sum_{v=1}^{3} F U_{t, f c}^{ \pm} V S_{t, r, v}^{ \pm}\left(F B_{t-1, v, f c}^{ \pm} R L_{r}+F S_{t-1, r, v, f c}^{ \pm}\right)
$$

Traffic management expense:

$$
\text { (2) }=\sum_{t=1}^{3} \sum_{r=1}^{r s} \sum_{v=1}^{3} k V S_{t, r, v}^{ \pm}
$$

Costs for capacity expansion of traffic facilities:

$$
\text { (3) }=\sum_{r t=1}^{r t s} N T_{r, r t} T C_{t, r t}^{ \pm}
$$

Maintenance expense:

$$
\text { (4) }=\sum_{t=1}^{3} \sum_{r}^{r s} \sum_{r t}^{r t s} R T_{r, r t}\left(R X_{t, r t}^{ \pm} R L_{r}+T F X_{t, r}^{ \pm}\right)
$$

Vehicle emission fee:

$$
\begin{aligned}
(5)= & \sum_{f c=1}^{3} \sum_{p t=1}^{3} \sum_{t=1}^{3} \sum_{r=1}^{r s} \sum_{v=1}^{3} F P_{t, p t}^{ \pm} V S_{t, r, v}^{ \pm} \\
& \left(F B_{t-1, v, f c}^{ \pm} R L_{r} W B_{p t, v, f c}+L_{t} F S_{t-1, r, v, f c}^{ \pm} W S_{p t, v, f c}\right)
\end{aligned}
$$

The constraints are listed as follows:

$$
\sum_{v=1}^{3} V S_{t, r, v}^{ \pm} \leq V T_{t, r} \quad \forall t, r ;
$$

$V T_{t, r}$ denotes the capacity limits of thoroughfare $r$ in period $t$. (b1) can ensure the amount of vehicle in thoroughfare $r$ in period $t$.

$$
\sum_{r=1}^{r s} V S_{t, r, i}^{ \pm} \leq \sum_{r=1}^{r s} \sum_{v t=1}^{3} V S_{t, r, v}^{ \pm} a_{i} \quad \forall t, i=1,2,3 ;
$$

(3b) can ensure all kinds of vehicle in a reasonable ratio in the whole transportation system.

$$
V S_{t, r, i}^{ \pm} \leq \sum_{v t=1}^{3} V S_{t, r, v}^{ \pm} b_{i} \quad \forall t, r, i=1,2,3 ;
$$

(3c) can ensure all kinds of vehicle in a reasonable ratio on every thoroughfare.

$$
\sum_{r=1}^{r s} \sum_{v t=1}^{3} f\left(v_{t, r}, V S_{t, r, v}\right)^{ \pm} \leq U P E_{t} \quad \forall t
$$

$U P E_{t}$ is the limitations of emissions of the whole system in period $t$.

$$
\sum_{v=1}^{3} f\left(v_{t, r}, V S_{t, r, v}\right)^{ \pm} \leq U P E R_{t, r} \quad \forall t, r ;
$$

$U P E R_{t, r}$ is the limitations of vehicle emissions of thoroughfare $r$ in period $t$.

$$
V S_{t, r, v}^{ \pm} \geq 0 \quad \forall t, r, v ;
$$

(3f) can ensure number of all kinds of vehicle on every thoroughfare in period $t$ in non negative.

$$
\sum_{r t=1}^{r t s} N T_{r, r t} T C_{t, r t}^{ \pm} \leq T C E_{t} \quad \forall t ;
$$

$T C E_{t}$ is the limitations of costs for capacity expansion of traffic facilities.

$$
\sum_{r}^{r s} \sum_{v=1}^{v t s} V S_{t, r, v}^{ \pm}=V S T_{t} \quad \forall t
$$

\section{Case Study}

As the modern urban agglomeration rapid development, the traffic structure has many similarities with land-use in a community. There are many uncertain factors that exit in the traffic system, such as weather condition, road condition, emission diffusion and so on. All of those lead to a problem that traffic system is difficult to formulate system planning model and generate a effective management scheme. A virtual city is considered in this study. There are two big plains in the city, with a traffic hinge, and many roads express ways passing though the study area. In this case, the planning model is simulated without any regulatory barriers (e.g. no punishment for driving a gas-guzzler). In the simulation of the reference case, the scheme will be chosen with the lowest cost. In 
the scenario, vehicle emissions are assumed to be stabilized during three planning periods. One prioritization scheme will be proposed to meet the environment standards. Date of the virtual case is shown in Tables $\mathbf{1}$ and $\mathbf{2}$.

\section{Results and Discussion}

Through solving the interval linear programming model, the optimal results would be expressed as interval numbers.

Figure 1 shows the solutions of the decision of vehicles (VSt,r,v ) under the scenario of no emission-limitation. It would be stable mainly on each thoroughfare in period 1 and period 2. But the decision of vehcles in period 3 is not similar to that in periods 1 and 2 .

Table 1. The Parameters of Five Thoroughfares.

\begin{tabular}{|c|c|c|c|c|c|}
\hline r & $\mathrm{t}$ & $\mathrm{RL}_{\mathrm{r}}(\mathrm{km})$ & Average vehicle Speed $(\mathrm{km} / \mathrm{h})$ & $\mathrm{RX}_{\mathrm{t}, \mathrm{rt}}($ million $\$ / \mathrm{km})$ & Maximum traffic flow allowed ( $10^{5}$ vehicle/day) \\
\hline \multirow{3}{*}{1} & 1 & \multirow{3}{*}{1.67} & {$[24.5,26.3]$} & {$[4.0,4.6]$} & \multirow{3}{*}{1.0} \\
\hline & 2 & & {$[23.5,24.5]$} & {$[4.5,5.2]$} & \\
\hline & 3 & & [22.6-23.3] & {$[5.5,5.8]$} & \\
\hline \multirow{3}{*}{2} & 1 & & {$[24.2,25.3]$} & {$[4.2,4.8]$} & \multirow{3}{*}{1.5} \\
\hline & 2 & 3.22 & {$[23.1,23.9]$} & {$[4.8,5.7]$} & \\
\hline & 3 & & {$[22.1,22.8]$} & {$[6.0,6.3]$} & \\
\hline \multirow{3}{*}{3} & 1 & & {$[38.2,40.5]$} & {$[20.0,22.0]$} & \multirow{3}{*}{0.75} \\
\hline & 2 & 3.65 & {$[36.4,38.1]$} & {$[23.0,24.5]$} & \\
\hline & 3 & & {$[34.8,37.2]$} & {$[27.0,28.0]$} & \\
\hline \multirow{3}{*}{4} & 1 & & {$[27.5,28.3]$} & {$[7.5,8.2]$} & \multirow{3}{*}{0.95} \\
\hline & 2 & 1.84 & {$[26.9,37.2]$} & {$[8.4,8.9]$} & \\
\hline & 3 & & {$[25.9,26.3]$} & {$[9.1,9.7]$} & \\
\hline \multirow{3}{*}{5} & 1 & & {$[30.5,31.2]$} & {$[20.1,20.5]$} & \multirow{3}{*}{1.05} \\
\hline & 2 & 1.75 & {$[29.5,30.2]$} & {$[21.3,22.0]$} & \\
\hline & 3 & & {$[27.9,28.6]$} & {$[22.4,23.0]$} & \\
\hline
\end{tabular}

Table 2. The Parameters of vehicle emissions.

\begin{tabular}{|c|c|c|c|c|c|c|c|}
\hline \multirow{2}{*}{$\mathrm{t}$} & \multirow{2}{*}{$\mathrm{V}$} & \multicolumn{3}{|c|}{$W B_{p t, v, f c}$} & \multicolumn{3}{|c|}{$W S_{p t, v, f c}$} \\
\hline & & fuel type1 & fuel type2 & fuel type3 & fuel type1 & fuel type2 & fuel type3 \\
\hline \multirow{3}{*}{1} & 1 & 0.059 & 0.048 & 0.067 & 0.11 & 0.1 & 0.12 \\
\hline & 2 & 0.062 & 0.053 & 0.067 & 0.12 & 0.11 & 0.11 \\
\hline & 3 & 0.073 & 0.06 & 0.076 & 0.13 & 0.12 & 0.11 \\
\hline \multirow[b]{2}{*}{2} & 1 & 0.0041 & 0.0043 & 0.0041 & 0.009 & 0.0091 & 0.01 \\
\hline & 2 & 0.0039 & 0.004 & 0.0038 & 0.0082 & 0.0089 & 0.0092 \\
\hline \multirow{3}{*}{3} & 1 & 0.42 & 0.41 & 0.4 & 0.52 & 0.53 & 0.54 \\
\hline & 2 & 0.39 & 0.4 & 0.39 & 0.51 & 0.51 & 0.51 \\
\hline & 3 & 0.41 & 0.39 & 0.41 & 0.51 & 0.5 & 0.49 \\
\hline
\end{tabular}

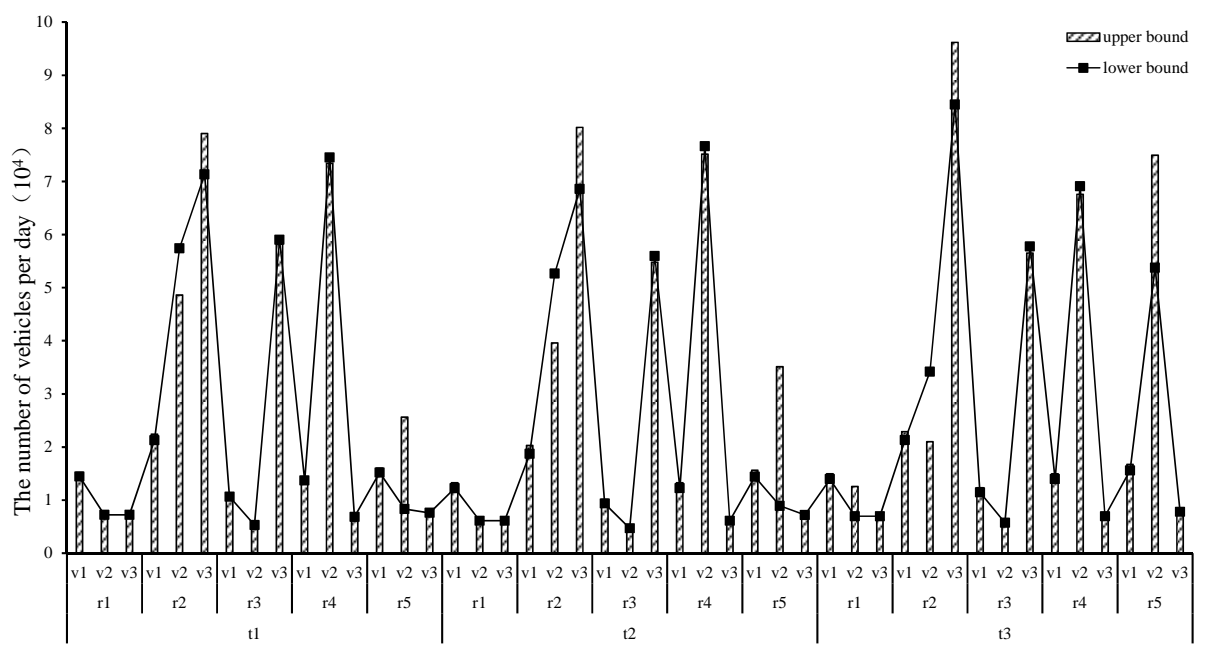

Figure 1. Solutions of decision variable $\left(V S_{t, r, v}\right)$ without the limitations of emissions. 
The system costs vary within [592.355, 1,163.926] million Yuan/year. The lower bound of the total costs (e.g. 592.355 million Yuan/year) would be obtained when decision of vehicles is at their lower bounds levels, and the upper bounds of the total costs (e.g. 1,163.926 million Yuan/year) can be obtained when VSt,r,v reach their upper bounds levels.

Figure 2 shows the solutions of the decision of vehicles (VSt,r,v ) under the scenario of emission-limitation. Thoroughfare 1 would have contion more vehicles under the scenario of emission-limitation than no emissionlimitation. Thoroughfare 2 would have contion most vechiles type 1 in period 3 .The decision of vehcles in thoroughfares 3, 4 and 5 would be stable mainly in each period. Under this scenario, the system costs vary within [357.450, 565.848] million Yuan/year.

The amount of CO emissions under different condi- tions is shown in Figure 3. Obviously, the amount of CO emissions without the constraints of emissions would be relative high, declining, and elevatory from periods 1 to 3 , respectively. In addition, the amount of $\mathrm{CO}$ emissions with unlimited emission constraint would be obviously biger than the amount of CO emissions under the scenario of with emission constraint.

Moreover, the amount of HC emissions under the consideration of unlimited- and limited-emission is shown in Figure 4. Obviously, the amount of HC emissions in unlimited-emission constraints is would be stable and excessive in each period. The amount of HC emissions in unlimited-emission scenarios would be relative high, declining, and elevatory from periods 1 to 3 ; and the quantity of HC emission would be relative high, declining, and elevatory under the scenarios of limited-emission constraints from periods 1 to 3 .

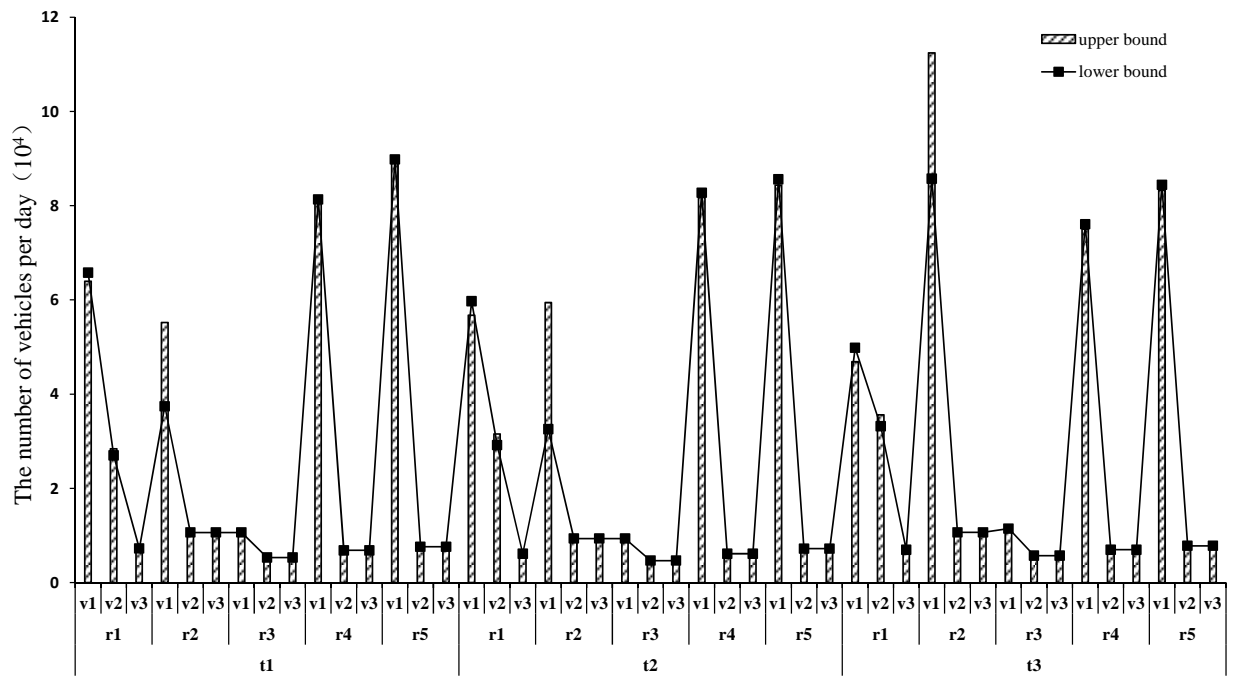

Figure 2. Solutions of decision variable $\left(V S_{t, r, v}\right)$ with the limitations of emissions.

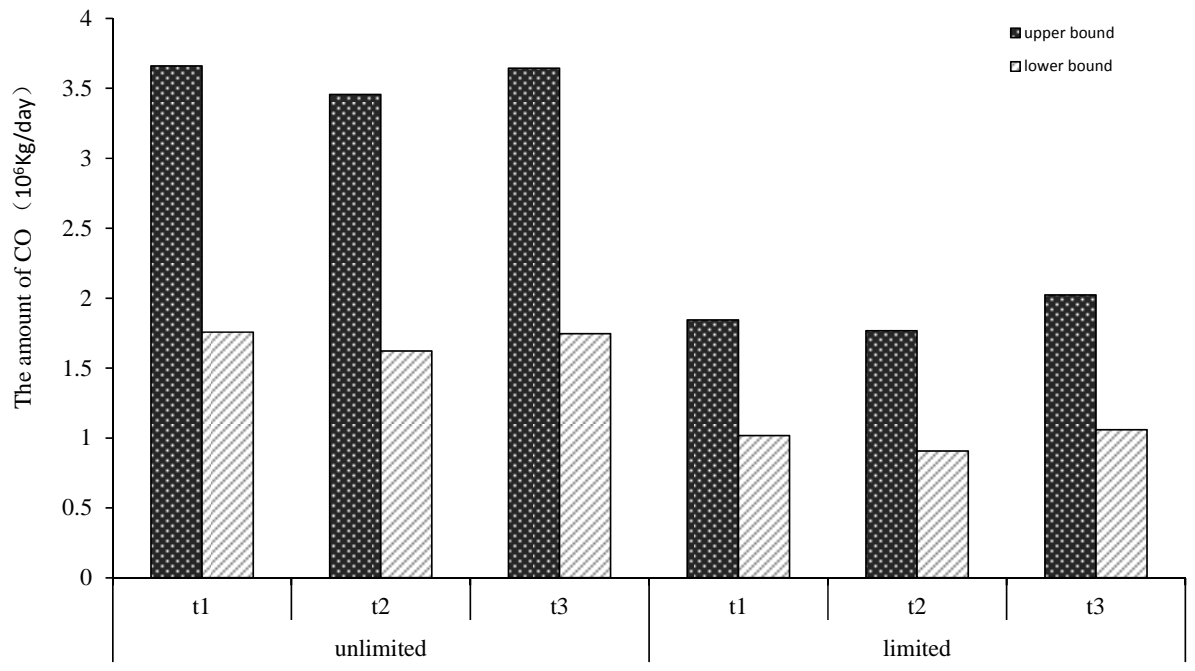

Figure 3. The amount of $\mathrm{CO}$ emissions during the planning horizon. 


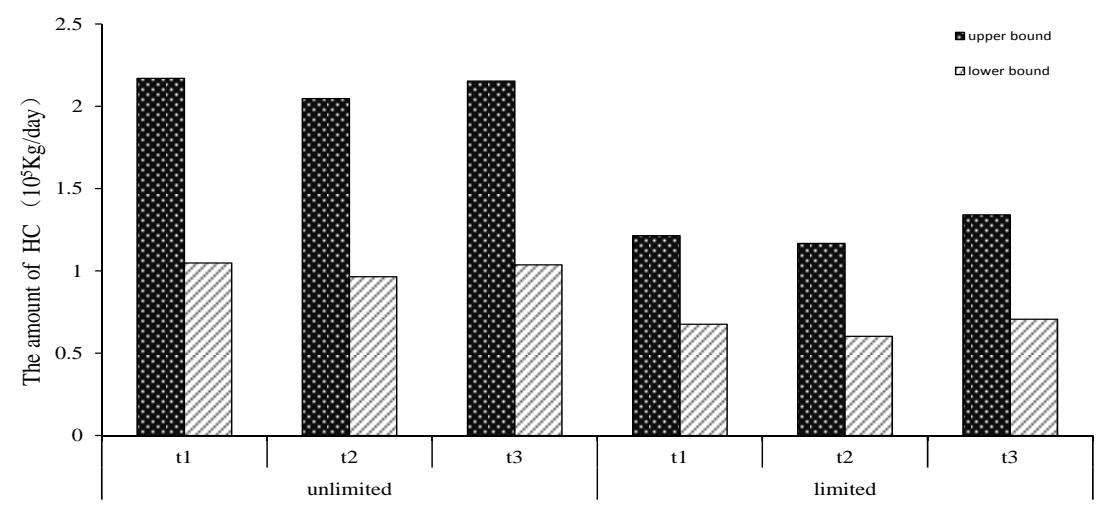

Figure 4. The amount of $\mathrm{HC}$ emissions during the planning horizon.

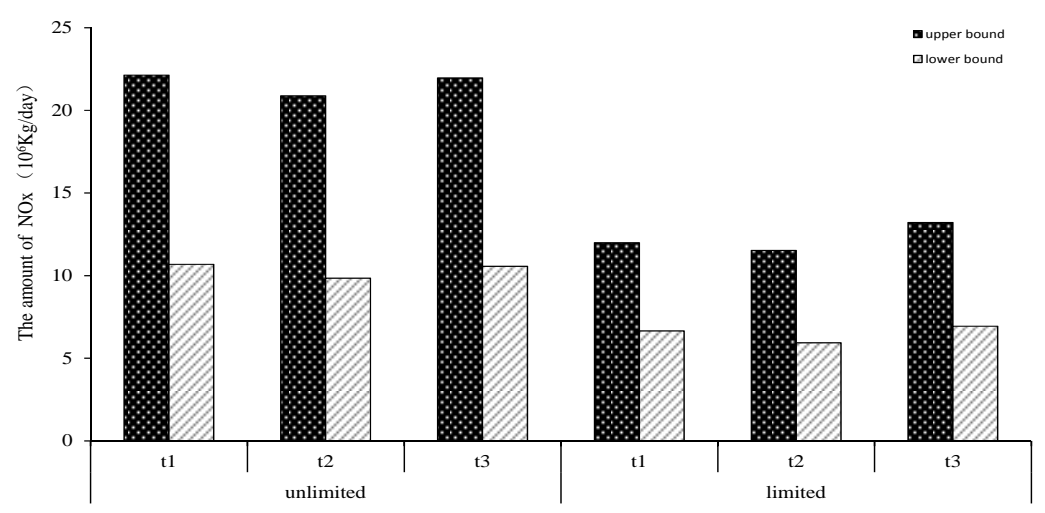

Figure 5. The amount of $\mathrm{NO}_{\mathrm{x}}$ emissions during the planning horizon.

Figure 5 shows the amount of NOx- emissions under different scenarios. It is indicated that, compared the value of the NOx-emissions, the amount of NOx-emissions reduction would be $54 \%$ and $62.2 \%$ during period 1 , $55.2 \%$ and $60.2 \%$ in period 2 , and $60.1 \%$ and $65.7 \%$ during period 3 . That is to say, the limitations of emissions are extraordinarily effectual. The results indicate that taking the reduction actions would decrease the amount of pollutants emission and keep a clear air quality.

\section{Conclusions}

Vehicle pollutant-emissions control is important for the whole society, and inter-community transportation planning becomes more and more significant. For this purpose, an interval planning and management model is developed to assess the minimum of system costs between communities. Through interval parameter linear programming methods within a general optimization framework, the model can deal with uncertainties expressed as interval value.

Previous achievements also focused on the transportation planning in a community or a region, and rarely developed optimization models for intercommunity trans- portation planning limitations of pollutant-emissions through the case study of traffic system in a virtual city. The results indicated that the model could effectively make a reasonable transportation plan for regional decision-makers.

\section{REFERENCES}

[1] M. C. Coelho, T. L. Farias and N. M. Rouphail, “A Numerical Tool for Estimating Pollutant Emissions and Vehicles Performance in Traffic Interruptions on Urban Corridors," International Journal of Sustainable Transportation, Vol. 3, No. 4, 2009, pp. 246-262.

doi:10.1080/15568310802175641

[2] A. D. Ellerman, B. K. Buchner and C. Carraro,“Allocation in the European Emissions Trading Scheme: Rights, Rents and Fairness," Cambridge: Cambridge University Press; 2007

[3] Z. Y. Gao, H. Z. Zhang and H. J. Sun, "Bilevel Programming Models, Approaches and Applicationsin Urban Transportation Network Design Problems," Journal of Transportation Systems Engineering and Information Technology, Vol. 4, No. 1, 2004, pp. 35-44.

[4] G. Huang, B. W. Baetz and G. G. Patry, “A Grey Fuzzy Linear Programming Approach for Municipal Solid Waste Management Planning under Uncertainty,” Civil 
Engineering and Environmental System, 1993, pp. 123-146.

[5] G. H. Huang, B. W. Baetz and G. G. Patry, "Grey Dynamic Programming for Solid Waste Management Planning under Uncertainty," Urban Plan. D-ASCE, pp. 132-156, 1994.

[6] G. H. Huang, N. Sae Lim, L. Liu and Z. Chen, “An Interval Parameter Fuzzy-stochastic Programming Approach for Municipal Solid Waste Management and Planning," Environmental Modeling And Assessment, Vol. 6, No. 4, 2001, pp. 271-283. doi:10.1023/A:1013394118863

[7] H. Iwata and K. Okada, "Greenhouse Gas Emissions and the Role of the Kyoto Protocol, M. S. Dissertation, Graduate School of Economics,” Kyoto University, Japan, 2010.

[8] B. Ling, “An Interval Stochastic Two-stage Linear Programming Approach for Managing CO2Emission Quota in Power Generation Sector,” M. S. Dissertation, Faculty of Graduate Studies and Research, Regina, Saskatchewan, Canada, 2006.

[9] Y. P. Li, G. H. Huang, S. L. Nie and Y. F. Huang "IFTSIP, "Interval Fuzzy Two-stage Stochastic Mixed-integer Linear Programming: A Case Study for Environmental
Management and Planning," Civil Engineering and Environmental Systems, Vol. 23, No. 2, 2006, pp. 73-99. doi:10.1080/10286600600679477

[10] Q. G. Lin and G. H. Huang, “An Inexact Two-Stage Stochastic Energy Systems Planning Model for Managing Greenhouse Gas Emission at a Municipal Level,” Energy, Vol. 35, No. 5, 2010, pp. 2270-2280.

doi:10.1016/j.energy.2010.01.042

[11] Z. Nahorski and J. Horabik "Greenhouse Gas Emission Permit Trading with Different Uncertainties in Emission Sources," Journal of Energy Engineering, pp. 52947-52952, 2008.

[12] A. Teller, "The Use of Linear Programming to Estimate the Cost of Some Alternatives Air Pollution Abatement Policies," Number 20 in IBM, 1968, pp. 345-53.

[13] X. P. Yan, X. F. Ma, G. H. Huang and C. Z. Wu, “An Inexact Transportation Planning Model for Supporting Vehicle Emissions Management," Journal of Environmental Informatics, 2010, pp. 87-98.

[14] E. Vine, "International Greenhouse Gas Trading Programs: A Discussion of Measurement and Accounting Issues,” Energy Policy, 2003.

\section{Appendix}

\begin{tabular}{|c|c|c|c|}
\hline$t$ & period & $r$ & thoroughfare \\
\hline rs & total amount of thoroughfares & $v$ & type of vehicle \\
\hline$p t$ & pollutant type (CO, $\mathrm{HC}, \mathrm{NO}_{\mathrm{x}}$ ) & $v t s$ & total amount of vehicle type $\mathrm{v}$ \\
\hline K & total management expence varies. & $F U_{t}, f c$ & the fuel prices \\
\hline$R L r$ & the length of thoroughfare $r$ & $F B_{t, v, f c}$ & the average consumption \\
\hline rts & total amount of thoroughfare types & $r t$ & thoroughfare type \\
\hline$N T_{r}, r t$ & is a binary variable for thoroughfares & $T C_{t}, r t$ & cost for building a new thoroughfare \\
\hline$R X_{t, r t}$ & the maintenance cost for thoroughfare & $R T_{r, r t}$ & binary variable for type $r t$ \\
\hline$f_{c}$ & fuel type & $V T_{t, r}$ & the capacity limits for thoroughfare $r$ \\
\hline$a_{i}$, & $\begin{array}{l}\text { Percentages to ensure vehicle in for whole } \\
\text { transportation system }\end{array}$ & $b_{i}$ & $\begin{array}{l}\text { Percentages to ensure vehicle on every } \\
\text { thoroughfare }\end{array}$ \\
\hline$U P E_{t, p t}$ & $\begin{array}{l}\text { the emissions limitations for the whole } \\
\text { system }\end{array}$ & $U P E R_{t, r}, p t$ & the emissions limitations thoroughfare $r$ \\
\hline$V S_{t, r, v t}$ & the amount of vehicles & $V S T_{t}$ & total amount of vehicle \\
\hline$F S_{t, r}, v, f c$ & fuel consumption & $W B_{p t, v, f c}$ & pollutant type $p t$ emission \\
\hline$W S_{p t, v, f c}$ & $\begin{array}{l}\text { pollutant type } p t \text { emission under idle } \\
\text { speed. }\end{array}$ & & \\
\hline
\end{tabular}

